\title{
Combination of supramolecular cross-linking with covalent cross-linking through epoxide ring-opening including gel studies
}

\author{
Harald Hofmeier $^{1,2}$, Abdelkrim El-ghayoury ${ }^{3}$, Ulrich S. Schubert ${ }^{1,2}$ *
}

${ }^{1}$ Laboratory of Macromolecular Chemistry and Nanoscience, Eindhoven University of Technology and Dutch Polymer Institute, P.O. Box 513, 5600 MB Eindhoven, The Netherlands; http://www.schubert-group.com; Fax +31-(0)40-247 4186; u.s.schubert@tue.nl

${ }^{2}$ Center for NanoScience, Ludwig-Maximilians-Universität München, GeschwisterScholl Platz 1, 80333 München, Germany

${ }^{3}$ Functional Polymers and Coatings, TNO Industrial Technology, De Rondom 1, P.O. Box 6235, 5600 HE Eindhoven, The Netherlands

(Received: August 21, 2003; published: October 9, 2003)

\begin{abstract}
Terpolymers based on poly(methyl methacrylate), containing terpyridinemoieties as well as epoxide groups, were synthesized via free-radical polymerization. The products were cross-linked non-covalently with iron(II) ions and covalently by treatment with $\mathrm{AlCl}_{3}$. Both steps could be combined in different order. The non-covalent cross-linking could be reversed by applying a strong competing ligand. The swelling behaviour of the polymers was investigated.
\end{abstract}

\section{Introduction}

A new research field in modern polymer chemistry is represented by the combination of supramolecular [1,2] and classical covalent [3] bonds and interactions. A promising approach towards this concept consists of the introduction of covalent and supramolecular cross-linking units as side chains into a terpolymer (Scheme 1).

This could be achieved by free-radical co- and terpolymerization of methyl methacrylate with functional methacrylates such as glycidyl methacrylate and a terpyridinecontaining methacrylate, which is a versatile method for the introduction of a variety of different functionalities into random co- and terpolymers. Furthermore, the functional monomers are easily accessible by reactions on methacrylic acid or methacryloyl chloride. The epoxide system is widely industrially used and the corresponding methacrylate monomer is commercially available. Poly(methyl methacrylate) turned out to be a suitable backbone for functional polymers, as terpyridine-modified methacrylates are easily accessible. The resulting terpolymer system could be subjected to two-step cross-linking, which may result in novel applications: the reversible nature and tunability of supramolecular bonds makes them interesting for the design of 'smart materials', e.g., switchable glues and adhesives or for self-repairing processes [4], while the ring-opening of epoxides is a 
well-known method for curing applications in coating technology. A suitable binding unit for supramolecular cross-linking is the 2,2':6',2"-terpyridine moiety [5]. This unit is able to form stable, but under certain conditions also fully reversible complexes with a variety of transition metal ions [6]. Through the use of different metal ions, the strength and reversible behaviour of the non-covalent interactions can be varied over a wide range. Whereas zinc(II), for example, forms relatively weak and reversible complexes, the analogous iron(II) or ruthenium(II) complexes are very strong and rather inert. The supramolecular cross-linking of ruthenium-containing copolymers has already been studied in diluted solutions [6b,7], but not yet under conditions, where highly cross-linked materials could be obtained. Depending on the concentration and the metal ions used, the viscosity behaviour of the solutions could be adjusted [6b]. Furthermore, the combination of supramolecular cross-linking with covalent cross-linking through cationic ring-opening polymerization of oxetanes has been demonstrated [8].

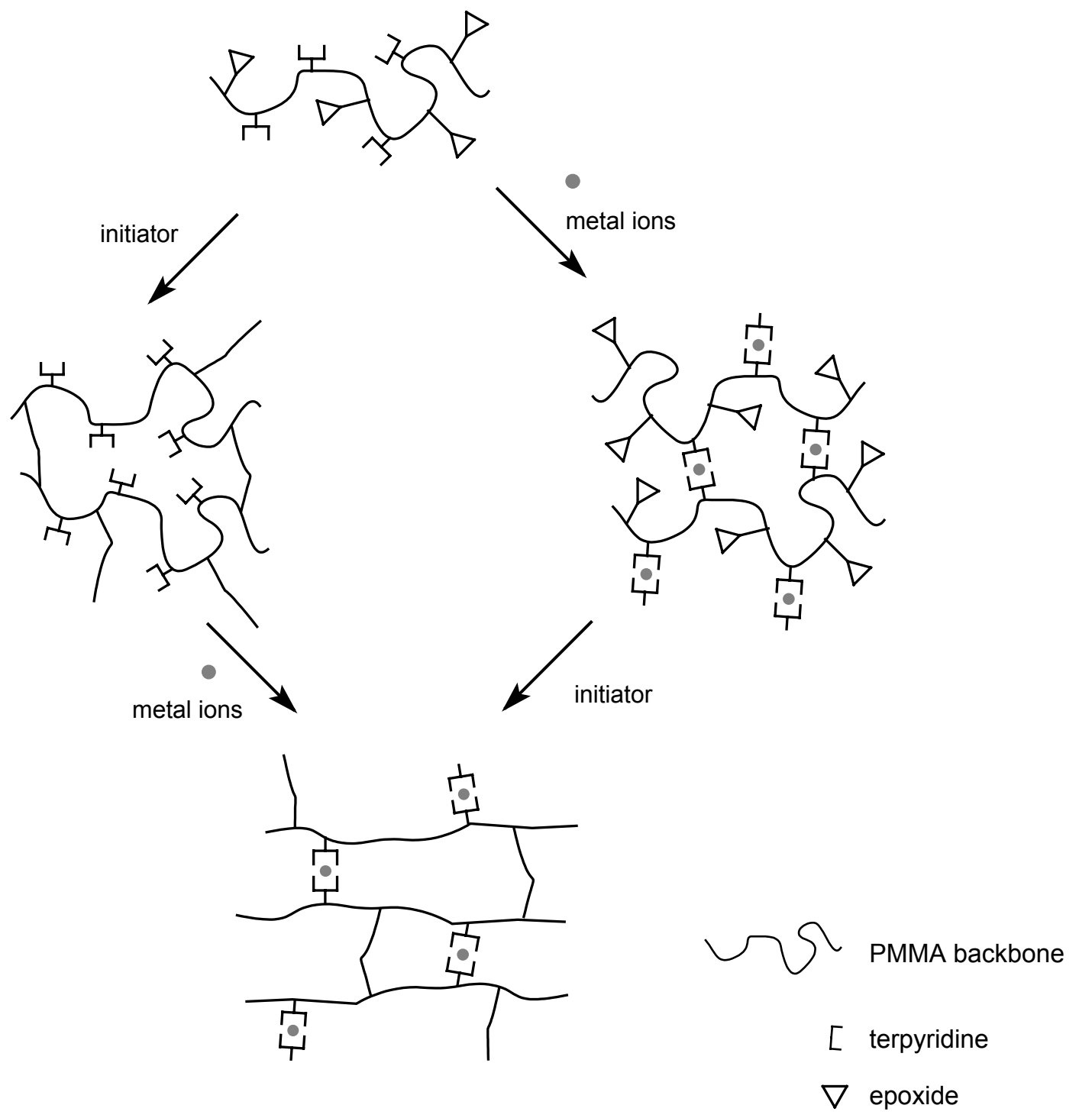

Scheme 1. Schematic overview of the cross-linking routes of terpolymers $\mathbf{4 c}$ and $\mathbf{4 d}$

In this contribution, we describe the non-covalent cross-linking of terpyridine under conditions, where gelation occurs, including investigations of the obtained materials. 
In addition, experiments combining the non-covalent cross-linking with covalent curing by ring-opening polymerization of epoxides were performed including studies of the cross-linking density.

\section{Results and discussion}

Terpolymers containing terpyridine as supramolecular binding unit and an epoxide group as covalent cross-linking unit [9] with two different compositions as well as two model copolymers have been synthesized by free radical polymerization utilizing 2,2'azoisobutyronitrile (AIBN) as initiator (Scheme 2 and Tab. 1).<smiles>C=C(C)C(=O)OCCCOc1cc(-c2ccccn2)nc(-c2ccccn2)c1</smiles>

1<smiles>C=C(C)C(=O)OC</smiles>

2 3

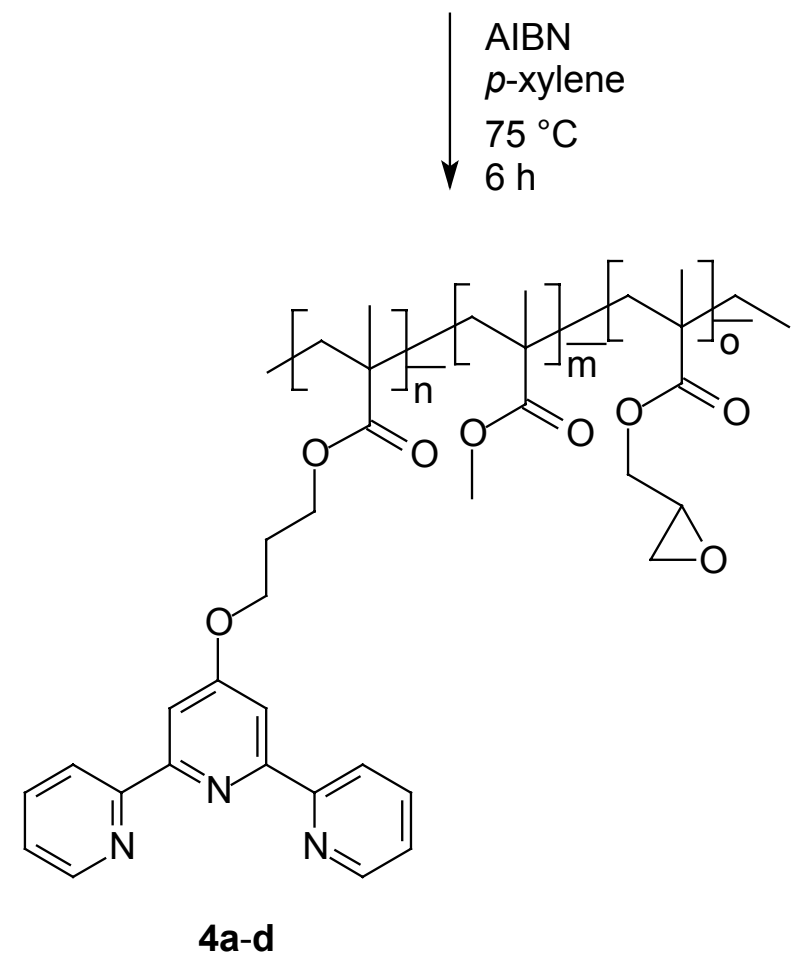

Scheme 2. Synthesis of the co- and terpolymers $4 \mathbf{a}-\mathbf{d}$

The products were precipitated into pentane and characterized with ${ }^{1} \mathrm{H}$ NMR and UVvis spectroscopy as well as gel permeation chromatography (GPC). The ${ }^{1} \mathrm{H}$ NMR spectra show the successful incorporation of all functional groups into the co- and terpolymers 4a-d (Fig. 1). 
Tab. 1. Characteristics of the co- and terpolymers $4 a-\mathbf{d}$

\begin{tabular}{cccccc}
\hline Polymer $^{\text {\% MMA }}$ & \% epoxide & \% terpy $^{\mathrm{a}}$ & $M_{\mathrm{n}}$ & $M_{\mathrm{w}} / M_{\mathrm{n}}$ \\
\hline 4a & 90 & 0 & 10 & 24300 & 2.3 \\
4b & 50 & 50 & 0 & 24700 & 5.9 \\
4c & 59 & 27 & 14 & 17000 & 2.7 \\
4d & 45 & 45 & 10 & 31700 & 5.5 \\
a mol-\% calculated from NMR integral ratios. & &
\end{tabular}

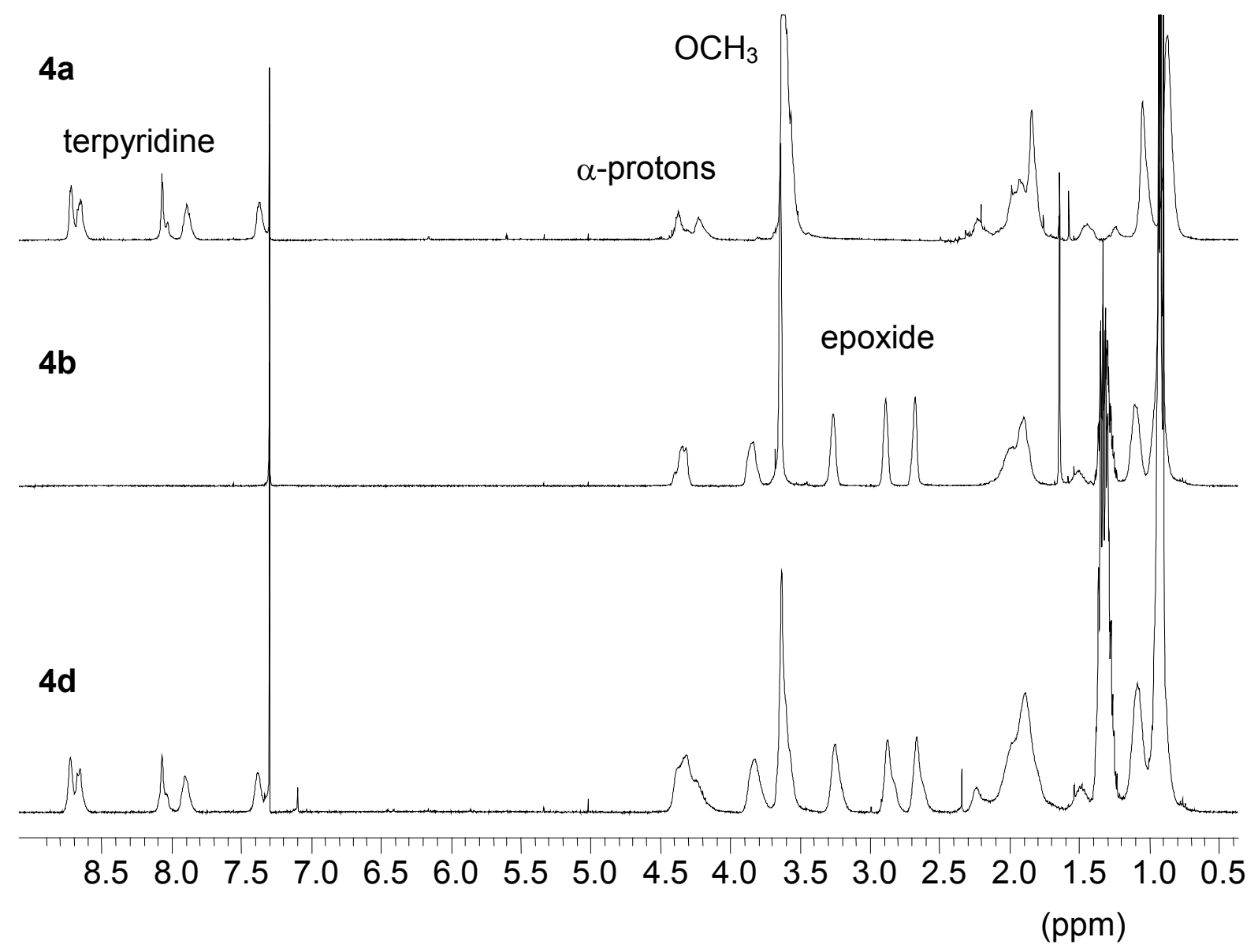

Fig. 1. ${ }^{1} \mathrm{H}$ NMR spectra of the co- and terpolymers $\mathbf{4 a}, \mathbf{4 b}$ and $\mathbf{4 d}$ (in chloroform)

The signals in the aromatic region could be assigned to the terpyridine units, the peak at $3.55 \mathrm{ppm}$ to the methyl group of the methyl methacrylate, and the signals between 2.5 and $3.5 \mathrm{ppm}$ to the epoxide protons. The main chain resonances were visible between 0.5 and $2 \mathrm{ppm}$.

Furthermore, IR investigations were performed on terpolymer $\mathbf{4 d}$ and the result compared with the model copolymers containing only terpyridine (4a) or epoxide (4b). The spectrum of $\mathbf{4 d}$ revealed the bands of both - terpyridine and epoxide units (Fig. 2). The epoxide peak was located at $908 \mathrm{~cm}^{-1}$ and the bands between 1540 and $1620 \mathrm{~cm}^{-1}$ were assigned to the terpyridine unit. GPC investigations revealed varying polydispersities and a negative tailing for the epoxide-containing polymers $\mathbf{4 b} \mathbf{b} \mathbf{d}$. 
A possible explanation could be a partial polymerization of the epoxide groups initiated by traces of acid during the reaction or during sample preparation.

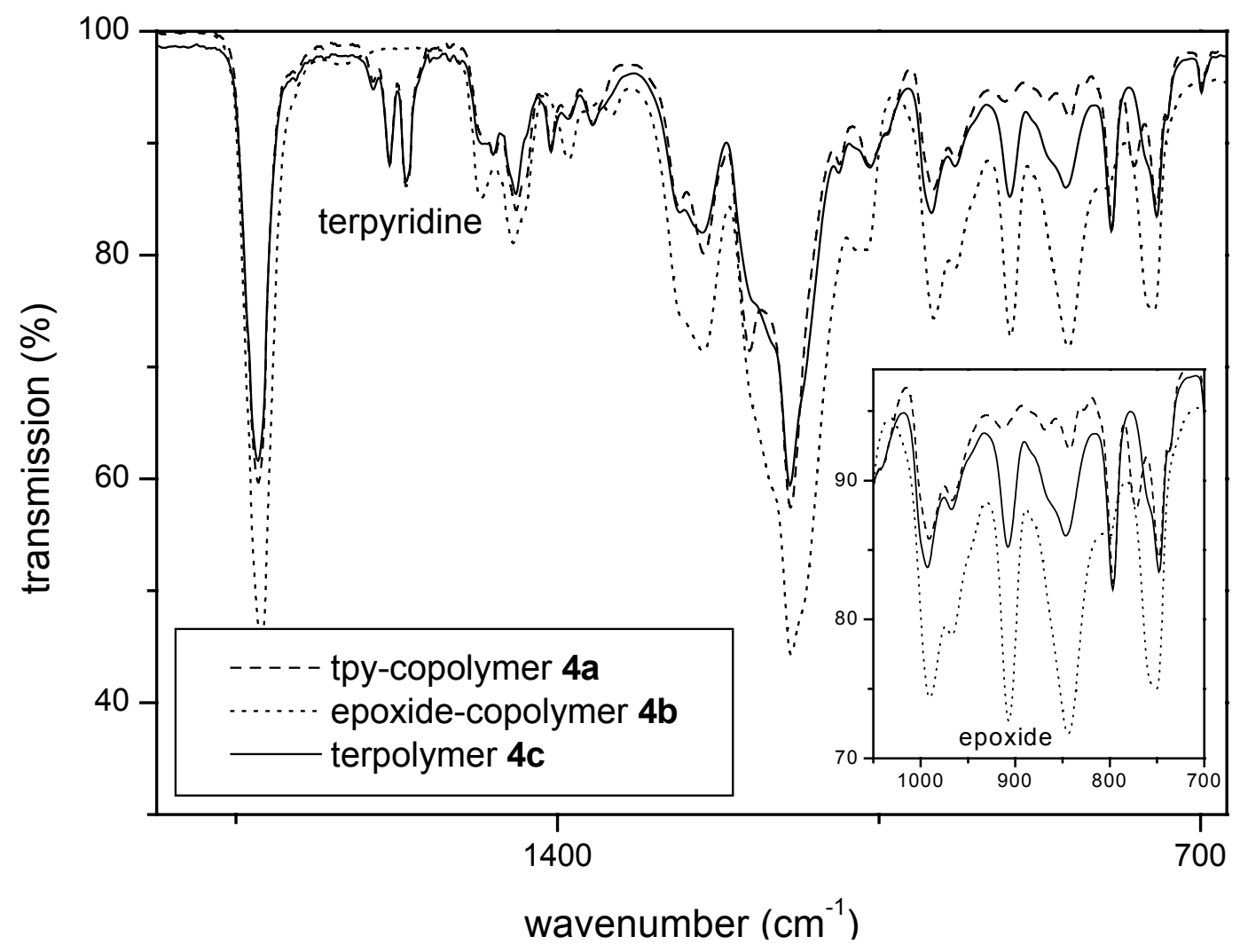

Fig. 2. IR spectrum of copolymers $\mathbf{4 a}$ and $\mathbf{4 b}$, and terpolymer $\mathbf{4 c}$

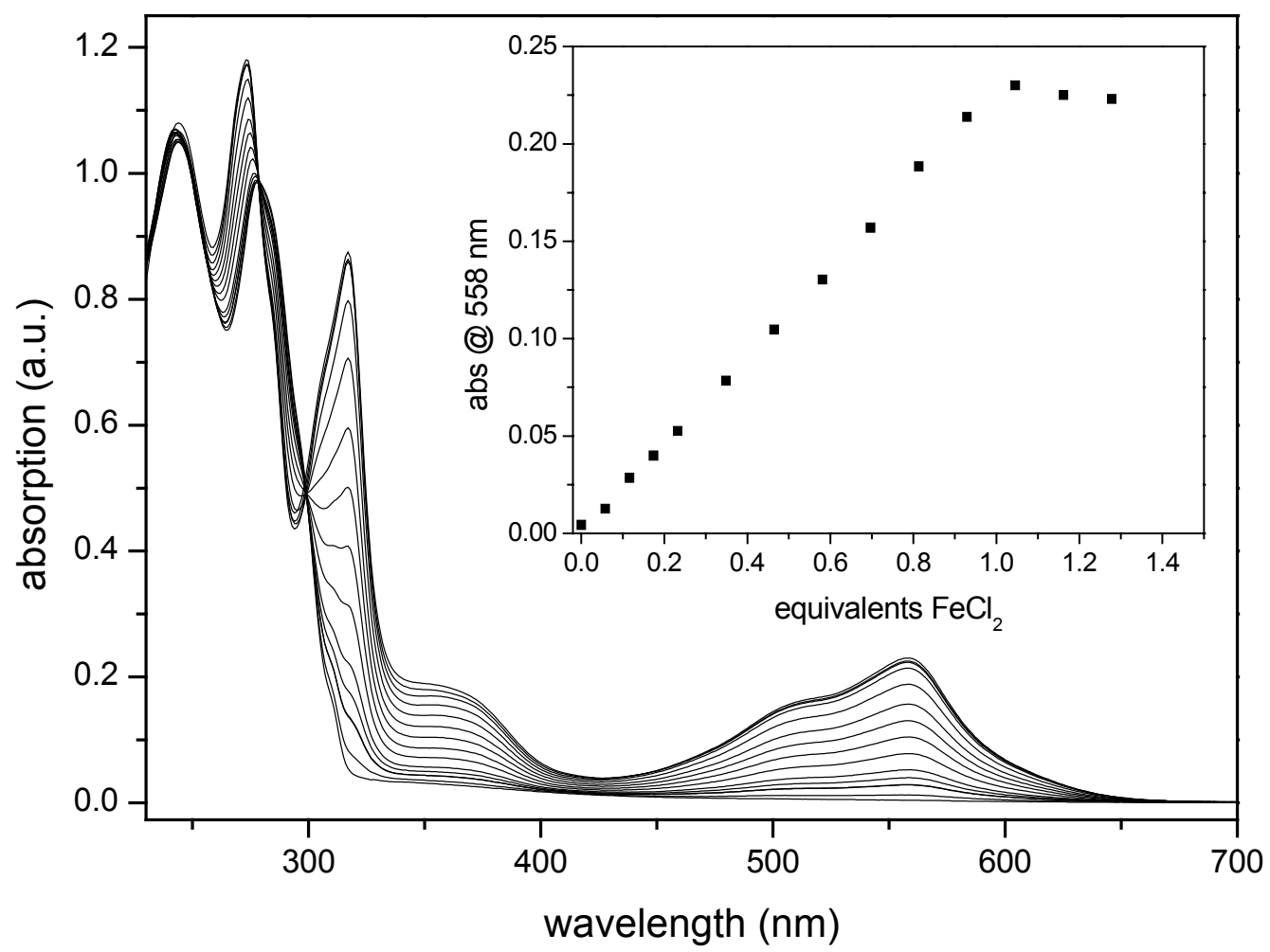

Fig. 3. UV-vis monitoring of the titration of terpolymer $4 \mathbf{c}$ with $\mathrm{Fe}(\mathrm{II})$ ions (in $\mathrm{CHCl}_{3}$ ) 
The terpolymer $\mathbf{4 d}$ was studied regarding its ability to combine covalent with supramolecular cross-linking. First, supramolecular cross-linking was studied through complexation of the terpyridine moieties with iron(II) ions. In order to prove the ability and completeness of complexation of the terpyridine units, a UV-vis titration experiment was performed by stepwise addition of an $\mathrm{FeCl}_{2}$ solution (in methanol) to a diluted chloroform solution of terpolymer $\mathbf{4 c}$ and by recording a spectrum $30 \mathrm{~min}$ after each addition (Fig. 3).

A characteristic bathochromic shift of the ligand-centred $\pi-\pi^{*}$-absorption bands from 279 to $317 \mathrm{~nm}$ was observed, showing a complexation of the terpyridine moieties. Furthermore, the appearance of the characteristic metal-to-ligand charge transfer (MLCT) band of the iron(II) complex at $558 \mathrm{~nm}$ and a metal-centred band at $358 \mathrm{~nm}$ was observed. The equivalence point was reached at an iron(II)/terpyridine ratio of $1: 2$, demonstrating the complete complexation of all terpyridine units. However, in diluted solutions, where the UV spectra were measured, the formation of intramolecular complexes or small aggregates can be expected. No precipitation was observed. To investigate the actual cross-linking, higher concentrations of the polymer, where gelation occurs, were applied: An appropriate amount of iron(II) ions (calculated from the NMR integral ratios) was added to copolymer 4a in chloroform, resulting in a deep purple gel. A sample of this gel was weighed in the swollen state, subsequently dried and weighed again. Re-swelling in chloroform led to the previous value, showing the reversible nature of the non-covalent cross-linked gel. $\mathrm{Zn}$ (II) ions at the same concentration led to a honey-like highly viscous solution, and at higher concentrations also gel formation was observed. In contrast to the iron-gel, the $\mathrm{Zn}$ (II) gel became completely soluble when more chloroform $(5 \mathrm{~mL})$ was added. An explanation for this behaviour is the reversible nature of zinc complexes, resulting in smaller aggregates by dilution. The addition of cobalt(II) ions led to a gel similar to that formed by iron(II) ions. In principle, the metal complexes are poorly soluble in chloroform, but in this case the polymer determines the solubility of the system. Nevertheless, the complexes could influence the swelling behaviour, although the effect could not yet be quantified.

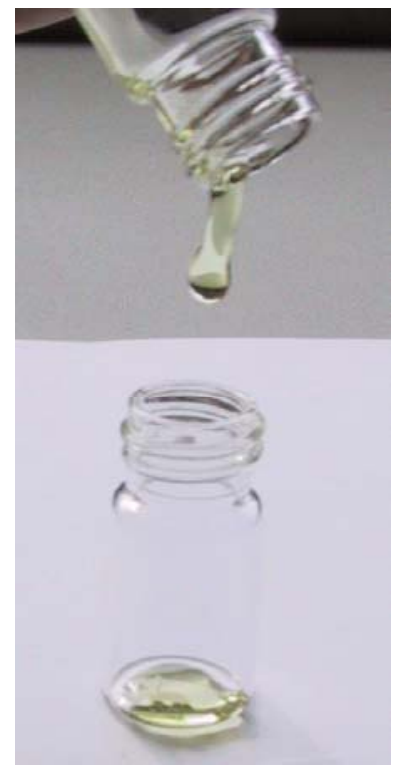

$\mathrm{ZnCl}_{2} 40 \mathrm{mg} / \mathrm{mL}$

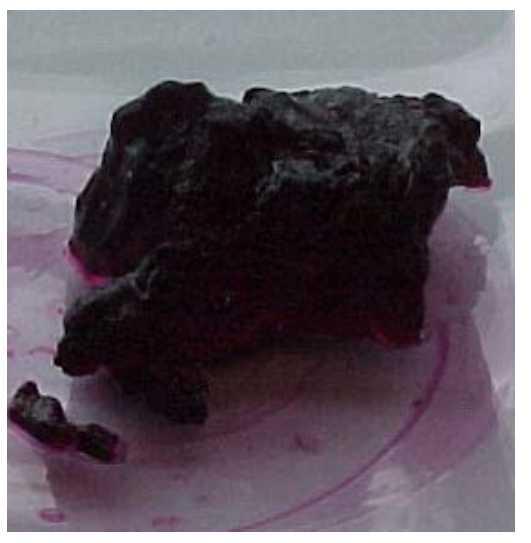

$\mathrm{FeCl}_{2} 42 \mathrm{mg} / \mathrm{mL}$

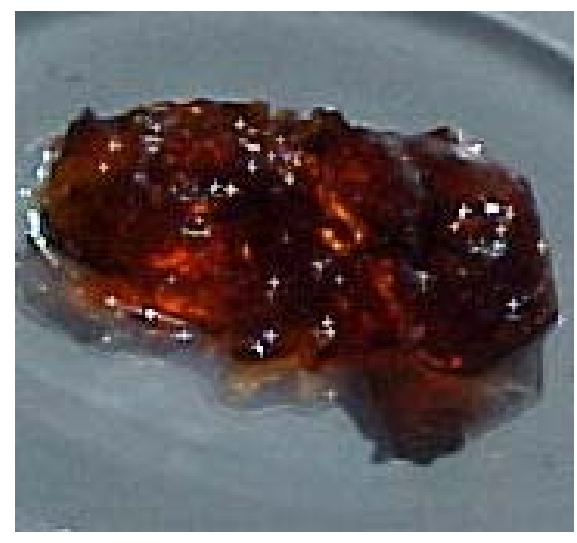

$\mathrm{Co}\left(\mathrm{NO}_{3}\right)_{2} 42 \mathrm{mg} / \mathrm{mL}$

Fig. 4. Gels of $4 a$ with zinc(II), iron(II) and cobalt(II) ions (chloroform) 
Covalent cross-linking was investigated using $\mathrm{AlCl}_{3}$ in order to open the epoxide rings (based on previous results with oxetane moieties reported in ref. [8]). Unlike boron trifluoride, $\mathrm{AlCl}_{3}$ was shown to open oxiranes without affecting the terpyridine ligands or complexes. In the first experiment, a solution of aluminium trichloride in dichloromethane was added to terpolymer $4 \mathbf{d}$ in dichloromethane (Exptl. part, route a). A precipitate of rubber-like flakes appeared immediately. The mixture was stirred at room temperature to complete the reaction. The ATR-FTIR spectra shown in Fig. 4 revealed a significant decrease of the epoxide C-O-C band at $908 \mathrm{~cm}^{-1}$ indicating that cationic ring-opening polymerization occurred, resulting in a covalently cross-linked material.

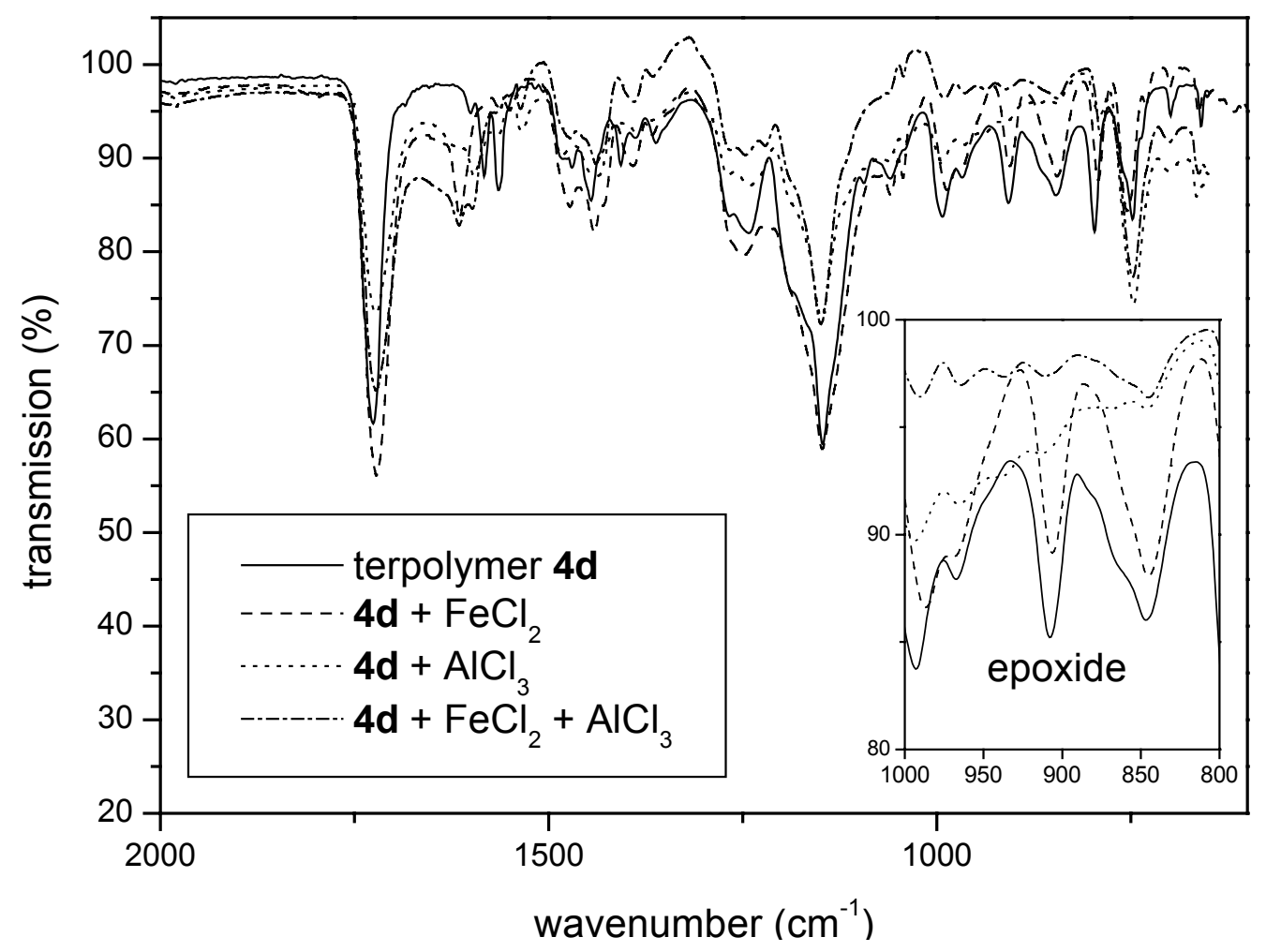

Fig. 5. IR spectra of terpolymer 4d: uncured, non-covalently cross-linked with $\mathrm{FeCl}_{2}$, covalently cross-linked with $\mathrm{AlCl}_{3}$, and cross-linked via both methods

Subsequently, experiments regarding the combination of supramolecular and covalent cross-linking were performed. First, an appropriate amount of iron(II) ions (calculated from the UV-vis titration results) was added to a solution of terpolymer $\mathbf{4 d}$ (30 mg/mL), which led to a deeply purple coloured and highly viscous solution (Exptl. part, route b). This non-covalently cross-linked polymer was treated in a second step with $\mathrm{AlCl}_{3}$ to initiate the cationic ring opening of the epoxide rings (route $\mathrm{c}$ ), resulting in a purple precipitate of the cross-linked material. As before, a significant decrease of the epoxide C-O-C peak at $908 \mathrm{~cm}^{-1}$ was observed. Another approach included the reversal of the order of the cross-linking reactions: the rubber-like material obtained from cross-linking of the uncomplexed terpolymer with $\mathrm{AlCl}_{3}$ (route a) was exposed to a methanolic solution of iron(II) chloride (route d). The colour turned to purple, first on the surface, but a subsequent deepening of the colouration indicated that complexation of the terpyridine groups, located inside the material sample, took place. The visual appearance of all the materials is shown in Fig. 6. 

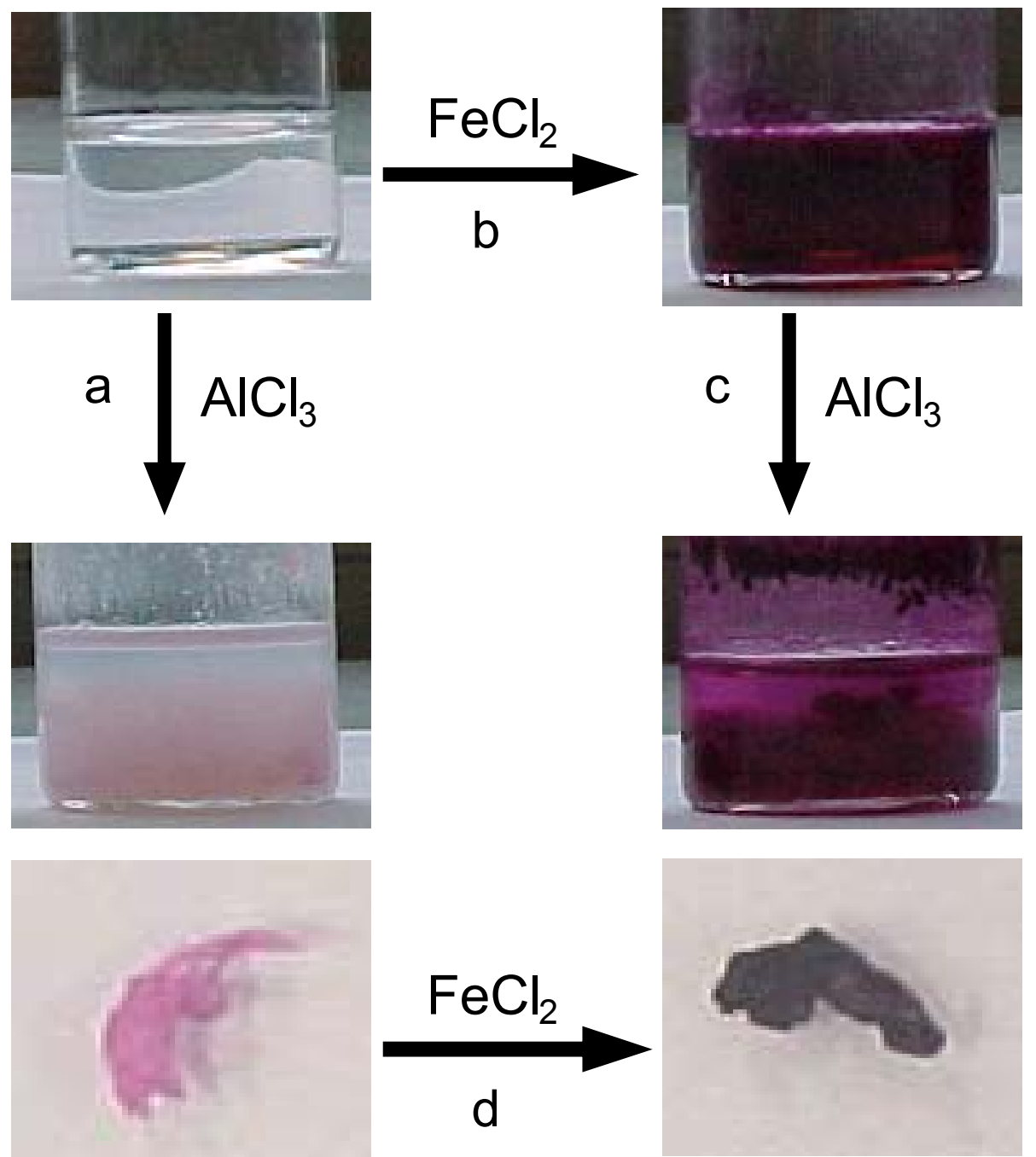

Fig. 6. Visual comparison of terpolymer $\mathbf{4 d}$ and the cross-linked materials

To investigate the cross-linking density, the swelling behaviour of the gels was studied. The covalently cross-linked gel from $\mathbf{4 d}$ (route a) as well as the material, which was cross-linked utilizing both covalent and supramolecular processes (route d), were investigated and compared to the gels obtained from $\mathbf{4 a}$, which contained only cross-links by terpyridine complexation. The gels were weighed in dry state and swollen with chloroform. From the obtained values the $Q$ factor was calculated applying the following formula:

$Q=\frac{a-b}{b}$

$a=$ weight of swollen gel, $b=$ weight of unswollen gel

The value $1 / Q$ is equivalent to the degree of cross-linking [10]. The gels derived from copolymer $\mathbf{4 a}$, consisting of non-covalent cross-links by Fe(II) or Co(II), revealed $1 / Q$ of 0.08 or 0.04 , respectively, whereas a value of 0.30 for the covalently cross-linked material derived from terpolymer $\mathbf{4 d}$ (route a) was found. These findings are consistent with the higher amount of epoxide moieties compared to terpyridine moieties in the respective polymers. Finally, in the material containing both covalent and supramolecular cross-links (route d), a value of 1.00 was found. These findings 
suggest that indeed both kinds of cross-links are present in the material and, therefore, increase the degree of cross-linking.

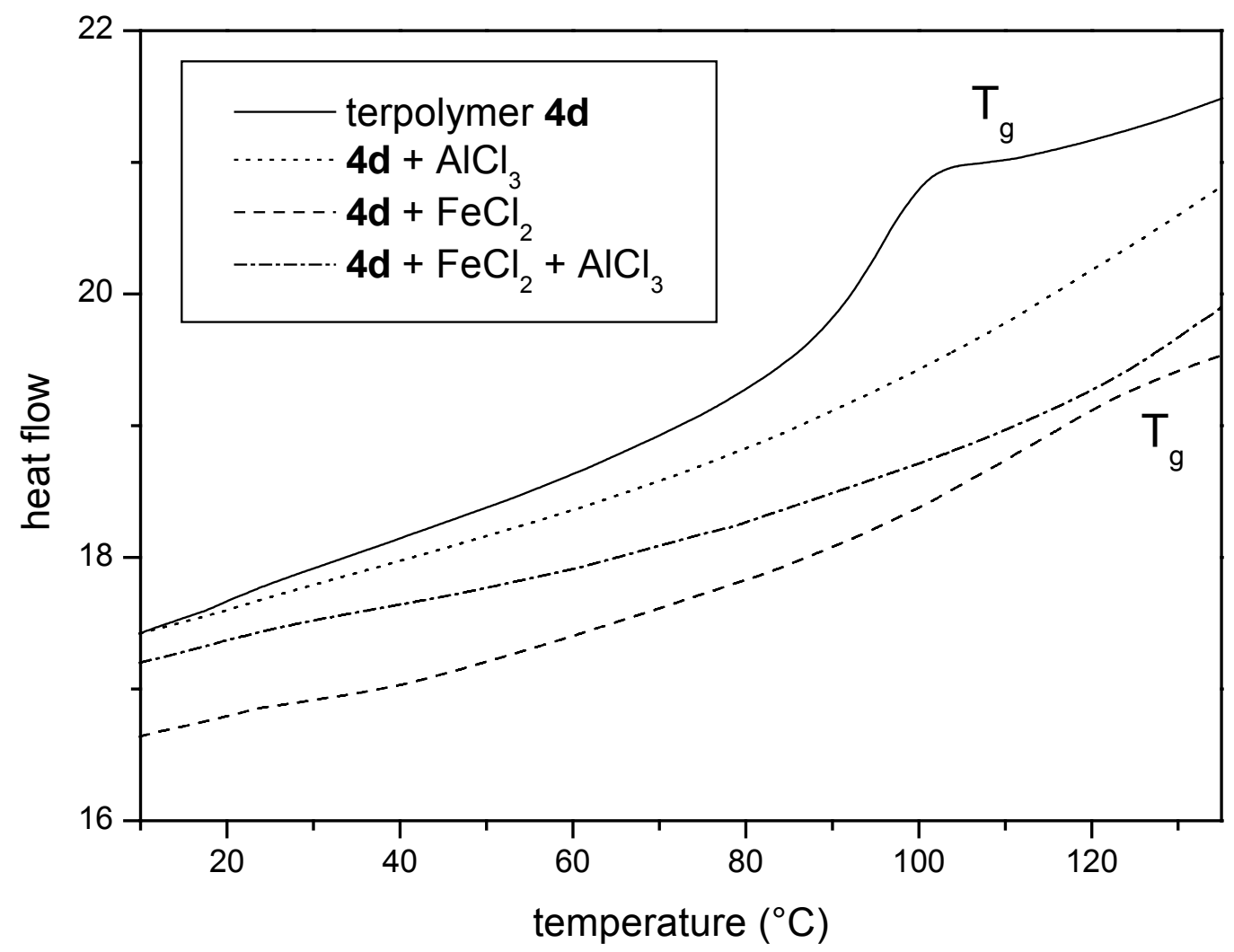

Fig. 7. Differential scanning calorimetry (DSC) thermograms of terpolymer $\mathbf{4 d}$ and the cross-linked materials

In order to determine the thermal properties of the initial terpolymer $\mathbf{4 d}$ as well as the corresponding cross-linked products, DSC investigations were performed (Fig. 7). Whereas terpolymer $\mathbf{4 d}$ revealed a glass transition at $92^{\circ} \mathrm{C}$, a weak transition at $119^{\circ} \mathrm{C}$ was found for the terpolymer, cross-linked with iron(II) ions. No transition (in the range of the measurement) was found for the covalently cross-linked material, due to the higher degree of cross-linking and the therefore lesser mobility of the chain segments. Finally, the material where both cross-linking approaches were combined was investigated. As expected, also in this case no glass transition was found. The results obtained from IR spectroscopy and DSC clearly indicate that supramolecular and covalent cross-linking steps can be combined successfully for the epoxide/ terpyridine system.

The supramolecular cross-linked gel was studied concerning the reversibility of complex formation. The gel obtained from $4 \mathrm{a}$ was exposed to the competing ligand hydroxyethylethylenediaminetetraacetic acid (HEEDTA, aqueous solution) in a chloroform/methanol mixture. Within $1 \mathrm{~h}$ the gel dissolved and the purple colour vanished.

\section{Conclusions and outlook}

Terpolymers, bearing terpyridine moieties as well epoxide groups, have been synthesized via free-radical terpolymerization and characterized with ${ }^{1} \mathrm{H} N M R$, UV-vis, FTIR 
as well as GPC. Supramolecular cross-linking of the terpolymers through complexation of the pending terpyridine units by addition of metal ions (iron(II), cobalt(II) and zinc(II)) has been successfully combined with covalent cross-linking by opening the epoxide rings, initiated with Lewis acids. The cross-linking behaviour has been studied by UV-vis, IR as well as DSC and the swelling behaviour of the obtained materials was investigated. Furthermore, the non-covalent cross-linking could be reversed by applying a strong competing ligand. In conclusion, with respect to previous results, the system has been optimized by applying a commercially interesting monomer (epoxide) and reaction conditions, where actual cross-linking (gel-formation) occurs. The demonstration of the reversibility of the cross-linked materials could be a milestone in the development of 'smart materials' such as reversible coatings. Future studies will include the application of the polymer in coating processes and the initiation of epoxide opening by other methods such as photoinitiation. Moreover, gel-swelling studies in different solvents will be performed.

\section{Experimental part}

\section{Materials and instrumentation}

Basic chemicals were obtained from Sigma-Aldrich and hydroxyethylethylenediaminetetraacetic acid (HEEDTA) from BASF. Acrylate compounds were distilled before use. Compound 1 was synthesized in a two-step reaction [11] from 4'-chloro$2,2^{\prime}: 6^{\prime}, 2^{\prime \prime}$-terpyridine [12]. NMR spectra were measured on a Varian Mercury 400 NMR spectrometer. Chemical shifts were calibrated to the residual solvent peaks. UV-vis spectra were recorded on a Perkin Elmer Lamda-45 (1 cm cuvettes) and IR spectra were taken on a Perkin Elmer Spectrum-1 ATR-FT-IR spectrometer. DSC investigations were performed on a Perkin Elmer Pyris-1 DSC system with a heating rate of $40 \mathrm{~K} / \mathrm{min}$ for determination of glass transitions. GPC measurements were performed on a Waters GPC apparatus using a $5 \mu \mathrm{m}$ PL-gel-mixed-D column (crosslinked polystyrene) with $N, N$-dimethylformamide (DMF) as eluent and a UV as well as a refractive index detector.

\section{Poly(methyl methacrylate-co-methacrylic acid 3-(2,2':6',2"-terpyridin-4'-yloxy)propyl ester) (4a)}

$1.33 \mathrm{~g}(13.3 \mathrm{mmol})$ of methyl methacrylate and $500 \mathrm{mg}(1.33 \mathrm{mmol})$ of 1 were dissolved in $2 \mathrm{~mL} p$-xylene and heated to $75^{\circ} \mathrm{C}$. Then $12 \mathrm{mg}(0.07 \mathrm{mmol})$ of $2,2^{\prime}-$ azobisisobutyronitrile (AIBN) was added and heating was continued for $6 \mathrm{~h}$. The mixture was precipitated twice in $20 \mathrm{~mL}$ pentane yielding $1.11 \mathrm{~g}(62 \%)$ of $4 \mathrm{a}$ as a white solid.

${ }^{1} \mathrm{H} \mathrm{NMR}\left(400 \mathrm{MHz}, \mathrm{CHCl}_{3}\right): \delta=0.83$ and $1.01\left(\mathrm{~b}, 26 \mathrm{H}, \mathrm{CH}_{3}\right), 1.80$ and $1.86(\mathrm{~b}, 18 \mathrm{H}$, $\mathrm{CH}_{2}$ ), 2.19 (m (b), $2 \mathrm{H}, \mathrm{CH}_{2}$ ), 3.58 (s, $\left.26 \mathrm{H}, \mathrm{OCH}_{3}\right), 4.19$ and 4.33 (m (b), $4 \mathrm{H}, \mathrm{OCH}_{2}$ ), $7.33\left(\mathrm{~m}, 2 \mathrm{H}, \mathrm{H}_{5,5^{\prime \prime}}\right), 7.85\left(\mathrm{~m}, 2 \mathrm{H}, \mathrm{H}_{4,4^{\prime \prime}}\right), 8.01$ (s, $\left.2 \mathrm{H}, \mathrm{H}_{3^{\prime}, 5^{\prime}}\right), 8.61\left(\mathrm{~m}, 2 \mathrm{H}, \mathrm{H}_{3,3^{\prime \prime}}\right), 8.67$ (m, $\left.2 \mathrm{H}, \mathrm{H}_{6,6 "}\right)$.

UV-vis $\left(\mathrm{CHCl}_{3}\right): \lambda_{\max }(\varepsilon)=279(445600), 245 \mathrm{~nm}\left(488100 \mathrm{~L} \cdot \mathrm{mol}^{-1} \cdot \mathrm{cm}^{-1}\right)$.

IR (ATR): 1/ = 2994 (m), 2950 (m), 1726 (s), 1601 (w, tpy), 1583 (m, tpy), 1565(m, tpy), $1470(\mathrm{~m}), 1445(\mathrm{~m}), 1407(\mathrm{~m}), 1384(\mathrm{w}), 1362(\mathrm{w}), 1268(\mathrm{~m}), 1241(\mathrm{~m}), 1191$ (s), $1146(\mathrm{~s}), 1060(\mathrm{~m}), 991(\mathrm{~m}), 968(\mathrm{~m}), 913(\mathrm{w}), 868(\mathrm{w}), 842(\mathrm{w}), 796(\mathrm{~m}), 772$ (m), $748(\mathrm{~m}), 699(\mathrm{w}), 660 \mathrm{~cm}^{-1}(\mathrm{w})$.

GPC (DMF): $M_{\mathrm{n}}=24330, M_{\mathrm{w}} / M_{\mathrm{n}}=2.29$. 
Poly(methyl methacrylate-co-methylepoxidyl methacrylate) (4b)

$465 \mathrm{mg}(4.65 \mathrm{mmol})$ of methyl methacrylate and $283 \mathrm{mg}(1.99 \mathrm{mmol})$ of 3 were dissolved in $2 \mathrm{~mL} p$-xylene and heated to $75^{\circ} \mathrm{C}$. Then $5.45 \mathrm{mg}(0.03 \mathrm{mmol})$ of AIBN was added and heating was continued for $6 \mathrm{~h}$. The mixture was precipitated twice in $20 \mathrm{~mL}$ pentane yielding $732 \mathrm{mg}(97 \%)$ of $\mathbf{4 b}$ as a white solid.

${ }^{1} \mathrm{H}$ NMR (400 MHz, $\left.\mathrm{CHCl}_{3}\right): \delta=0.87$ and $1.03\left(\mathrm{~b}, 6 \mathrm{H}, \mathrm{CH}_{3}\right), 1.84$ and $1.93(\mathrm{~m}(\mathrm{~b}), 4$ $\mathrm{H}, \mathrm{CH}_{2}$ ), 2.64 (s, $1 \mathrm{H}$, epoxide), 2.85 (s, $1 \mathrm{H}$, epoxide), 3.22 (s, $1 \mathrm{H}$, epoxide), 3.60 (s, $\left.3 \mathrm{H}, \mathrm{OCH}_{3}\right), 3.80\left(\mathrm{~m}(\mathrm{~b}), 1 \mathrm{H}, \mathrm{OCH}_{2}\right), 4.30$ (m (b), $\left.1 \mathrm{H}, \mathrm{OCH}_{2}\right)$.

UV-vis $\left(\mathrm{CHCl}_{3}\right): \lambda_{\max }(\varepsilon)=269(3100), 2276 \mathrm{~nm}\left(2900 \mathrm{~L} \cdot \mathrm{mol}^{-1} \cdot \mathrm{cm}^{-1}\right)$.

IR (ATR): 1/入 = $2994(\mathrm{~m}), 2950(\mathrm{~m}), 1726(\mathrm{~s}), 1470(\mathrm{~m}), 1445(\mathrm{~m}), 1407(\mathrm{~m}), 1384$ (w), $1362(\mathrm{w}), 1268(\mathrm{~m}), 1241(\mathrm{~m}), 1191(\mathrm{~s}), 1146(\mathrm{~s}), 1060(\mathrm{~m}), 991(\mathrm{~m}), 968(\mathrm{~m})$, 908 (m, epoxide), 847 (m, epoxide), $796(\mathrm{~m}), 748(\mathrm{~m}), 699(\mathrm{w}), 660 \mathrm{~cm}^{-1}(\mathrm{w})$.

GPC (DMF): $M_{\mathrm{n}}=24660, M_{\mathrm{w}} / M_{\mathrm{n}}=5.85$, negative tailing.

Poly(methyl methacrylate-co-methacrylic acid 3-(2,2':6',2"-terpyridin-4'-yloxy)propyl ester-co-methylepoxidyl methacrylate) (4c)

$437 \mathrm{mg}(3.41 \mathrm{mmol})$ of methyl methacrylate, $250 \mathrm{mg}(1.25 \mathrm{mmol})$ of 1 and $106 \mathrm{mg}$ $(0.29 \mathrm{mmol})$ of 3 were dissolved in $2 \mathrm{~mL} p$-xylene and heated to $65^{\circ} \mathrm{C}$. Then $12 \mathrm{mg}$ $(0.12 \mathrm{mmol})$ of benzoyl peroxide (BPO) was added and heating was continued for $10 \mathrm{~h}$. The mixture was precipitated twice in $20 \mathrm{~mL}$ pentane followed by size exclusion chromatography yielding $556 \mathrm{mg}(0.075 \mathrm{mmol}, 70 \%)$ of 3 as a white solid.

${ }^{1} \mathrm{H} \mathrm{NMR}\left(400 \mathrm{MHz} \mathrm{CHCl}_{3}\right): \delta=0.87$ and $1.03\left(\mathrm{~b}, 24 \mathrm{H}, \mathrm{CH}_{3}\right), 1.84\left(\mathrm{~b}, 17 \mathrm{H}, \mathrm{CH}_{2}\right)$, 2.19 (m (b), $2 \mathrm{H}, \mathrm{CH}_{2}$ ), 2.63 (s, $2 \mathrm{H}$, epoxide), 2.84 (s, $2 \mathrm{H}$, epoxide), 3.21 (s, $2 \mathrm{H}$, epoxide) 3.59 (s, $16 \mathrm{H}, \mathrm{OCH}_{3}$ ), 4.43 (m (b), $4 \mathrm{H}, \mathrm{OCH}_{2}$ ), 7.36 (m, $\left.2 \mathrm{H}, \mathrm{H}_{5,5 "}\right), 7.88$ (dd, $\left.2 \mathrm{H}, J=7.32,7.32 \mathrm{~Hz}, \mathrm{H}_{4,4^{\prime \prime}}\right), 8.06\left(\mathrm{~s}, 2 \mathrm{H}, \mathrm{H}_{3^{\prime}, 5^{\prime}}\right), 8.63$ (d, $\left.2 \mathrm{H}, J=7.32 \mathrm{~Hz}, \mathrm{H}_{3,3^{\prime \prime}}\right), 8.70$ (d, $\left.2 \mathrm{H}, J=5.86 \mathrm{~Hz}, \mathrm{H}_{6,6 "}\right)$.

UV-vis $\left(\mathrm{CHCl}_{3}\right): \lambda_{\max }(\varepsilon)=279(52300), 246 \mathrm{~nm}\left(54800 \mathrm{~L} \cdot \mathrm{mol}^{-1} \cdot \mathrm{cm}^{-1}\right)$.

IR (ATR) 1/ג = $2994(\mathrm{~m}), 2950$ (m), 1726 (s), 1601 (w, tpy), 1583 (m, tpy), 1565(m, tpy), $1470(\mathrm{~m}), 1445(\mathrm{~m}), 1407(\mathrm{~m}), 1384(\mathrm{w}), 1362(\mathrm{w}), 1268(\mathrm{~m}), 1241(\mathrm{~m}), 1191$ (s), $1146(\mathrm{~s}), 1060(\mathrm{~m}), 991(\mathrm{~m}), 968(\mathrm{~m}), 908$ (m, epoxide), 847 (m, epoxide), 796 (m), $748(\mathrm{~m}), 699(\mathrm{w}), 660 \mathrm{~cm}^{-1}(\mathrm{w})$.

GPC $\left(\mathrm{CHCl}_{3}\right): M_{\mathrm{n}}=17000, M_{\mathrm{w}} / M_{\mathrm{n}}=2.7$, negative tailing.

Poly(methyl methacrylate-co-methacrylic acid 3-(2,2':6',2"-terpyridin-4'-yloxy)propyl ester-co-methylepoxidyl methacrylate) (4d)

$478 \mathrm{mg}(4.78 \mathrm{mmol})$ of methyl methacrylate, $300 \mathrm{mg}(0.67 \mathrm{mmol})$ of 1 and $340 \mathrm{mg}$ $(2.39 \mathrm{mmol})$ of 3 were dissolved in $2 \mathrm{~mL} p$-xylene and heated to $75^{\circ} \mathrm{C}$. Then $6.5 \mathrm{mg}$ $(0.03 \mathrm{mmol})$ of AIBN was added and heating was continued for $6 \mathrm{~h}$. The mixture was precipitated twice in $20 \mathrm{~mL}$ pentane yielding $1.08 \mathrm{~g}(96 \%)$ of $\mathbf{4 d}$ as a white solid.

${ }^{1} \mathrm{H}$ NMR (400 MHz, $\left.\mathrm{CHCl}_{3}\right): \delta=0.87$ and $1.03\left(\mathrm{~b}, 27 \mathrm{H}, \mathrm{CH}_{3}\right), 1.85\left(\mathrm{~b}, 20 \mathrm{H}, \mathrm{CH}_{2}\right)$, 2.19 (m, $2 \mathrm{H}, \mathrm{CH}_{2}$ ), 2.63 (s, $4.5 \mathrm{H}$, epoxide), 2.84 (s, $4.5 \mathrm{H}$, epoxide), 3.21 (s, $4.5 \mathrm{H}$, epoxide), 3.59 (s, $\left.13 \mathrm{H}, \mathrm{OCH}_{3}\right), 4.43$ (m (b), $\left.4 \mathrm{H}, \mathrm{OCH}_{2}\right), 7.34\left(\mathrm{~m}, 2 \mathrm{H}, \mathrm{H}_{5,5^{\prime \prime}}\right), 7.86(\mathrm{~m}$, $\left.2 \mathrm{H}, \mathrm{H}_{4,4^{\prime \prime}}\right), 8.03\left(\mathrm{~s}, 2 \mathrm{H}, \mathrm{H}_{3^{\prime}, 5^{\prime}}\right), 8.63\left(\mathrm{~m}, 2 \mathrm{H}, \mathrm{H}_{3,3^{\prime \prime}}\right), 8.69\left(\mathrm{~m}, 2 \mathrm{H}, \mathrm{H}_{6,6^{\prime \prime}}\right)$.

UV-vis $\left(\mathrm{CHCl}_{3}\right): \lambda_{\max }(\varepsilon)=279(421100), 246 \mathrm{~nm}\left(427600 \mathrm{~L} \cdot \mathrm{mol}^{-1} \cdot \mathrm{cm}^{-1}\right)$. 
IR (ATR): 1/ = $2994(\mathrm{~m}), 2950$ (m), 1726 (s), 1601 (w, tpy), 1583 (m, tpy), 1565(m, tpy), $1470(\mathrm{~m}), 1445(\mathrm{~m}), 1407(\mathrm{~m}), 1384(\mathrm{w}), 1362(\mathrm{w}), 1268(\mathrm{~m}), 1241(\mathrm{~m}), 1191$ (s), $1146(\mathrm{~s}), 1060(\mathrm{~m}), 991(\mathrm{~m}), 968(\mathrm{~m}), 908$ (m, epoxide), 847 (m, epoxide), 796 (m), $748(\mathrm{~m}), 699(\mathrm{w}), 660 \mathrm{~cm}^{-1}(\mathrm{w})$.

GPC (DMF): $M_{\mathrm{n}}=31650, M_{\mathrm{w}} / M_{\mathrm{n}}=5.47$, negative tailing.

\section{UV-vis titration of $\mathbf{4 c}$}

$4.1 \mathrm{mg}$ of $4 \mathrm{c}$ was dissolved in $50 \mathrm{~mL}$ of chloroform. A $1.62 \cdot 10^{-4} \mathrm{M}$ solution of iron(II) chloride (in methanol) was added in steps of $40 \mu \mathrm{L}$ while the mixture was stirred; 15 min after every addition a spectrum was recorded.

\section{Covalent cross-linking of the terpolymer $\mathbf{4 d}$}

Route a: $65 \mathrm{mg}$ of $\mathbf{4 d}$ were dissolved in $10 \mathrm{~mL}$ of dichloromethane. Subsequently $1 \mathrm{~mL}$ of a solution of $\mathrm{AlCl}_{3}$ in dichloromethane was added and the mixture was allowed to react for $2 \mathrm{~h}$.

Route $b$ : To $65 \mathrm{mg}$ of $\mathbf{4 d}$ in $10 \mathrm{~mL}$ of dichloromethane were added $3 \mathrm{mg}$ of iron(II) chloride in $1 \mathrm{~mL}$ of methanol.

Route $c$ : The product obtained from (b) was treated with $\mathrm{AlCl}_{3}$ as described in (a).

Route $d$ : A sample of the material obtained from (a) was covered with dichloromethane, and $30 \mu \mathrm{L}$ of a methanolic solution of $\mathrm{FeCl}_{2}\left(8 \cdot 10^{-3} \mathrm{M}\right)$ were added.

\section{Gel formation studies}

Solutions of $\mathrm{FeCl}_{2}, \mathrm{ZnCl}_{2}$ and $\mathrm{Co}\left(\mathrm{NO}_{3}\right)_{2}(0.5 \mathrm{~mL}$ of $0.14 \mathrm{M}$ solutions in methanol) were added to solutions ( $2 \mathrm{~mL}, 42 \mathrm{mg} / \mathrm{mL}$ ) of copolymer $4 \mathrm{a}$ in chloroform. The obtained gel and the gels yielded from $\mathbf{4 d}$ (routes $b$ and $d$ ) were weighed in the swollen state (chloroform) as well as in the dry state and the swelling factors $Q$ were calculated.

Acknowledgement: This study was supported by Deutsche Forschungsgemeinschaft (SFB 486), Fonds der Chemischen Industrie, and Dutch Polymer Institute (DPI).

[1] (a) Schubert, U. S.; Eschbaumer, C.; Angew. Chem. 2002, 114, 3016; Angew. Chem. Int. Ed. 2002, 41, 2892. (b) Brunsveld, L.; Folmer, B. J. B.; Meijer, E. W.; Sijbesma, R. P.; Chem. Rev. 2001, 101, 4071.

[2] (a) Rieth, L. R.; Eaton, R. F.; Coates, G. W.; Angew. Chem. 2001, 113, 2211; Angew. Chem. Int. Ed. 2001, 40, 2153. (b) Chino, K.; Ashiura, M.; Macromolecules 2001, 34, 9201.

[3] (a) Roffey, C. C.; "Photopolymerization of Surface Coatings", Wiley, Chichester 1982. (b) Pappas, S. P.; "UV-Curing Science and Technology", Technology Marketing, Stanford, CT 1978 and 1985, vols. 1 and 2. (c) El-ghayoury, A.; Boukaftane, C.; De Ruiter, B.; van der Linde, R.; J. Polym. Sci., Part A: Polym. Chem. 2003, 414, 469. 
[4] (a) Schubert, U. S.; Heller, M.; Chem. Eur. J. 2001, 7, 5252. (b) Schubert, U. S.; Hochwimmer, G.; Schmatloch, S.; Hofmeier, H.; Eur. Coat. J. 2003, 28, 31,34.

[5] (a) Schubert, U. S.; Eschbaumer, C.; Andres, P. R.; Hofmeier, H.; Weidl, C. H.; Herdtweck, E.; Dulkeith, E.; Morteani, A.; Hecker, N. E.; Feldmann, J.; Synth. Met. 2001, 121, 1249. (b) Kelch, S.; Rehahn, M.; Macromolecules 1999, 32, 5818. (c) Kelch, S.; Rehahn, M.; Chem. Commun. 1999, 1123. (d) Schubert, U. S.; Hien, O.; Eschbaumer, C.; Macromol. Rapid Commun. 2000, 21, 1156.

[6] (a) Heller, M.; Schubert, U. S.; Macromol. Rapid Commun. 2001, 22, 1358. (b) Hofmeier, H.; Schubert, U. S.; Macromol. Chem. Phys. 2003, 204, 1391.

[7] (a) Hanabusa, K.; Nakamura, A.; Koyama, T.; Shirai, H.; Makromol. Chem. 1992, 193, 1309. (b) Calzia, K. J.; Tew, G. N.; Macromolecules 2002, 35, 6090.

[8] El-ghayoury, A.; Hofmeier, H.; de Ruiter, B.; Schubert, U. S.; Macromolecules 2003, 36, 3955.

[9] Reviews on the cationic ring-opening polymerization: Penczek, S.; Kubisa, P.; "Cationic Ring-Opening Polymerization: Ethers", in 'Comprehensive Polymer Science', G. Allen, editor; Pergamon Press, Oxford 1989, p. III/751.

[10] (a) Tai, H.-J.; Wang, J. B.; Chen, J.-H.; Chou, H.-L.; J. Appl. Polym. Sci. 2001, 79, 652. (b) Flory, P. J.; "Principles in Polymer Chemistry", Cornell Univ. Press, Ithaca, New York 1953.

[11] Schubert, U. S.; Hofmeier, H.; Macromol. Rapid Commun. 2002, 23, 561.

[12] Schubert, U. S.; Schmatloch, S.; Precup, A. A.; Design. Monom. Polym. 2002, 5, 211. 